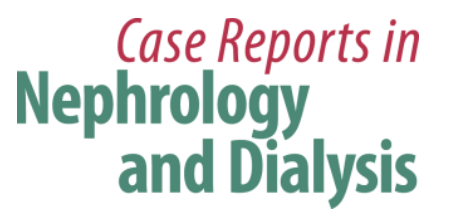

\title{
Efficacy of Semiannual Single Fixed Low-Dose Rituximab Therapy in Steroid-Dependent Minimal Change Nephrotic Syndrome: A Case Series
}

\author{
Ryosuke Usui $^{a} \quad$ Yohei Tsuchiya $^{a} \quad K$ Kosaku Nitta ${ }^{b}$ Minako Koike \\ aDivision of Nephrology, Department of Medicine, Yachiyo Medical Center, Tokyo \\ Women's Medical University, Chiba, Japan; ${ }^{b}$ Department of Medicine, Kidney Center, \\ Tokyo Women's Medical University, Tokyo, Japan
}

\section{Keywords}

Rituximab · Refractory nephrotic syndrome - Steroid-dependent nephrotic syndrome

\begin{abstract}
The frequency of using rituximab to treat refractory nephrotic syndrome has recently been increasing, and the conventional dose of rituximab used to treat it, $375 \mathrm{mg} / \mathrm{m}^{2}$ body surface area once weekly for 4 weeks, has been modelled on the chemotherapy regimen for B-cell non-Hodgkin's lymphoma. The dose and intervals of rituximab in refractory nephrotic syndrome remain controversial. Clear lymphoma cell hyperplasia is seen in lymphoma patients, but not in nephrotic syndrome patients. Since we thought that it might be possible to reduce the dose of rituximab if only used for the purpose of depleting CD20-positive B cells in nephrotic patients' peripheral blood, we tried semiannually with a single fixed rituximab dose of $100 \mathrm{mg} / \mathrm{body}$, and a complete remission was attained in 3 cases without treatment with
\end{abstract}




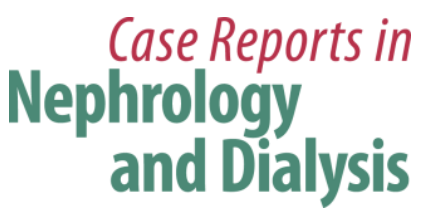

Case Rep Nephrol Dial 2018;8:230-237

prednisolone or cyclosporine. Our report strongly suggests considering appropriate dose and interval of rituximab therapy in the treatment of steroid-dependent nephrotic syndrome.

(C) 2018 The Author(s)

Published by S. Karger AG, Basel

\section{Introduction}

Patients with nephrotic syndrome due to primary glomerulonephritis are usually treated with immunosuppressive drugs such as steroids, cyclosporine, cyclophosphamide, mizoribine, and mycophenolate mofetil. In almost all cases, a steroid is administered as the firstline drug, and another immunosuppressant is used as a second-line drug in combination with steroid when sufficient efficacy is not achieved with the steroid alone. There are two types of refractory nephrotic syndrome: steroid-dependent nephrotic syndrome (SDNS) and steroidresistant nephrotic syndrome, and long-term treatment of either type with steroids has various adverse effects such as obesity, moon face, susceptibility to infection, gastric ulcer, hypertension, diabetes, dyslipidemia, osteoporosis, glaucoma, and cataract. In some cases, femur head necrosis, cataract, and adrenocortical insufficiency are irreversible adverse effects due to long-term use of steroids.

The Ministry of Health, Labour and Welfare of Japan recently approved rituximab as a treatment for refractory nephrotic syndrome, and although reports of its efficacy have accumulated, the dose and interval to use for rituximab therapy are still controversial.

\section{Rituximab Therapy}

The first intravenous infusion of rituximab was done at the single dose of $375 \mathrm{mg} / \mathrm{m}^{2}$ body surface area (BSA) (maximum dose $500 \mathrm{mg} /$ body). To reduce infusion reactions, we administered $4 \mathrm{mg}$ of betamethasone (intravenously), $40 \mathrm{mg}$ of monoammonium glycyrrhizinate (intravenously), $400 \mathrm{mg}$ of acetaminophen (orally), and $2 \mathrm{mg}$ of d-chlorpheniramine maleate (orally) to each patient $30 \mathrm{~min}$ prior to the rituximab infusion, and the subsequent infusion intervals and dose of rituximab were 6 months and $100 \mathrm{mg} /$ body, respectively.

\section{Case Report}

The clinical course and summarized profile of each case are shown in Figure 1 and Table 1 , respectively.

\section{Case 1 (Clinical Course)}

The patient in case 1 (Fig. 1a) was a Japanese male with minimal change disease (MCD) diagnosed at the 16 years of age. Initial treatment with prednisolone $60 \mathrm{mg} /$ day decreased his urinary protein level, but 2 weeks after the start of treatment his urinary protein level rebounded. Subsequently, administration of cyclosporine and introduction of low-density lipoprotein absorption resulted in a complete remission. However, the MCD relapsed 2-4 times a 


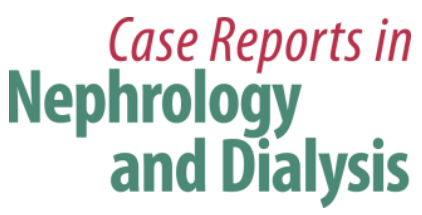

Case Rep Nephrol Dial 2018;8:230-237

year accompanied by reduction in prednisolone dose, i.e. the patient had SDNS. Two years and 7 months after its onset, we administered a dose of $500 \mathrm{mg} /$ body of rituximab (BSA was $1.72 \mathrm{~m}^{2}$ ). The dose of the second and later rituximab infusions was $100 \mathrm{mg} /$ body at 6 -month intervals. Prednisolone was discontinued after the second rituximab infusion, and cyclosporine was discontinued after the third infusion. The patient has received 7 rituximab treatments thus far (total dose: 1,100 mg), and a complete remission has been maintained for over 3 years after the start of rituximab. At the time of first infusion, the patient felt his face was glowing, but it improved in a few minutes without additional medication, and there have been no subsequent adverse effects.

\section{Case 2 (Clinical Course)}

The patient in case 2 (Fig. 1b) was a Japanese male with MCD that was diagnosed at 16 years of age. Initial treatment with prednisolone $60 \mathrm{mg} /$ day resulted in a complete remission, but relapses occurred about twice a year when the prednisolone dose was reduced, i.e. the patient had SDNS. We administered a $500 \mathrm{mg} /$ body dose of rituximab (BSA was $1.73 \mathrm{~m}^{2}$ ) at 22 months after the diagnosis. The subsequent infusion doses of rituximab have been 100 $\mathrm{mg} /$ body every 6 months. Prednisolone and cyclosporine were discontinued at the time of second infusion. After the initial rituximab infusion, a complete remission was maintained over 18 months. The patient has received rituximab 4 times so far (total dose: $800 \mathrm{mg}$ ), no adverse effects have been observed.

\section{Case 3 (Clinical Course)}

The patient in case 3 (Fig. 1c) was a Japanese male who was diagnosed with MCD at 41 years of age. His MCD had been managed well with prednisolone and cyclosporine, but it had relapsed 2-3 times a year repeatedly when the dose of prednisolone was reduced, i.e. he had SDNS. Five years and 6 months after its onset, we administered a dose of $500 \mathrm{mg} / \mathrm{body}$ of rituximab (BSA was $1.60 \mathrm{~m}^{2}$ ). Six weeks after the first infusion of rituximab, the patient developed a fever with upper respiratory infection symptoms accompanied by neutropenia (neutrophils 317 cells $/ \mu \mathrm{L}$ ), which were consistent with febrile neutropenia (FN). Treatment with filgrastim $75 \mu \mathrm{g}$ and cefepime $4 \mathrm{~g}$ /day was followed by an immediate improvement in the patient's condition. Prednisolone and cyclosporine were discontinued 14 weeks after the first rituximab infusion, but the MCD did not relapse. Although FN is a very severe adverse effect of rituximab, the patient wished to receive a second rituximab administration, because he was very satisfied with its efficacy, i.e. a complete remission, without prednisolone and cyclosporine. We administered a dose of $100 \mathrm{mg} /$ body of rituximab 6 months after the first infusion. Three infusions of rituximab have been administered thus far (total dose: $700 \mathrm{mg}$ ), but they were not followed by neutropenia and FN despite the absence of preventive administration of filgrastim. A complete remission has been maintained for over a year after the initial dose of rituximab.

\section{Discussion}

MCD is a common cause of nephrotic syndrome. Most MCD cases can be managed well with steroids [1], but a third to two-thirds of MCD patients experience frequent relapses or 


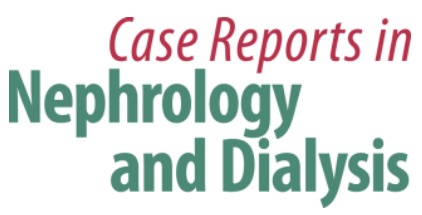

Case Rep Nephrol Dial 2018;8:230-237

become steroid-dependent [2]. As it is impossible to predict whether MCD will follow a refractory clinical course, many patients develop adverse effects of long-term steroid use.

Rituximab is a chimeric anti-CD20 monoclonal antibody that depletes CD20-positive B cells and improves the symptoms of patients with malignant lymphoma [3] and autoimmune diseases $[4,5]$. Efficacy of rituximab in pediatric cases of refractory SDNS has been reported in the past decade [6, 7]. In Japan, the achievement by Iijima et al. [8], namely confirmation of the usefulness of rituximab in the frequently relapsing nephrotic syndrome and SDNS, contributed to obtaining approval for the use of rituximab in the treatment of refractory nephrotic syndrome from the Ministry of Health, Labour and Welfare in 2014.

The optimal way to use rituximab for the treatment of refractory nephrotic syndrome is still controversial. Since rituximab was produced and used clinically to treat B cell lymphoma, the dose and/or intervals of rituximab administration to treat nephrotic syndrome, i.e. 375 $\mathrm{mg} / \mathrm{m}^{2}$ BSA once weekly for 4 weeks, has been modelled on the regimen used to treat lymphoma. However, nephrotic syndrome is a very different disease from lymphoma. Lymphoma patients hold the evident hyperplasia of lymphoma cell, but nephrotic syndrome patients do not. We thought it would be possible to reduce the dose of rituximab when used to deplete CD20-positive B cells in nephrotic syndrome patients' peripheral blood. Our institution has repeatedly reported a sustaining effect for half a year with single-dose rituximab $375 \mathrm{mg} / \mathrm{m}^{2}$ [9-12].

A phase I trial of rituximab targeting at the lymphoma patients confirmed that a 100 $\mathrm{mg} / \mathrm{m}^{2}$ dose of rituximab could sufficiently deplete CD20-positive B-cells in the peripheral blood, and that an even lower dose of $50 \mathrm{mg} / \mathrm{m}^{2}$, which is compatible with about $100 \mathrm{mg} /$ body, can reduce the CD20-positive B cell count [13]. Actually, in our 3 cases of MCD, CD19/20positive B cells were completely depleted by a single low-dose rituximab infusion, and this effect persisted and maintained complete remission until the next dose of rituximab (Fig. 1). In case 1 , we checked the CD20-positive B-cell count 3 times before administering rituximab, and the counts (cells $/ \mu \mathrm{L}$ ) were 534,86 , and 106 , respectively, suggesting that determining the rituximab dose based on CD20-positive B-cell count is unrealistic. Moreover, since the peripheral blood CD20-positive B-cell count is independent of BSA, the meaning of correction according to BSA is unclear. Back calculating the rituximab doses according to BSA in our 3 cases yielded $57 \mathrm{mg} / \mathrm{m}^{2}$ in case 1 and case 2 , and $62 \mathrm{mg} / \mathrm{m}^{2}$ in case 3 , all of which were about onesixth the conventional dose.

Although rituximab can be used safely and is well tolerated in most cases, various adverse effects, including infusion reactions, neutropenia, reactivation of hepatitis B virus, interstitial pneumonia, and progressive multifocal leukoencephalopathy have been reported, and infusion reactions have been observed at a constant frequency in nephrotic syndrome patients treated with rituximab $[7,8,11]$. Unfortunately, the development of fatal pulmonary fibrosis after rituximab administration has been reported in a pediatric patient with refractory nephrotic syndrome that did not respond to conventional treatments [14]. The patient in case 3 in this report developed FN 6 weeks after the first rituximab infusion, and there may be concern about unclear and/or as-yet-unknown adverse effects of rituximab, e.g. as a result of its effects on gonad function and newly onset of autoimmune disease. All drugs have numerous adverse effects, and we should prescribe the minimum dose as a means of reducing the risk of adverse effects. 


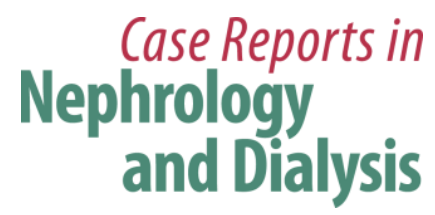

\begin{tabular}{l|l} 
Case Rep Nephrol Dial 2018;8:230-237 \\
\hline DOI: 10.1159/000493189 & $\begin{array}{l}\text { @ } 2018 \text { The Author(s). Published by S. Karger AG, Basel } \\
\text { www.karger.com/cnd }\end{array}$
\end{tabular}

Kamei et al. [15] reported discontinuing steroid therapy in all patients with refractory SDNS after starting treatment with rituximab, whereas Iijima et al. [8] reported that all participants in their trial had relapsed by 19 months after randomization, suggesting that rituximab is highly effective in refractory SDNS, but that its efficacy is insufficient to achieve a radical cure. Although long-term safety of rituximab in refractory SDNS patients has not been demonstrated, rituximab may play an important role in avoiding severe adverse effects of steroids. It has been reported that treatment with rituximab can allow reduction of the steroid dose and ameliorate the adverse effects of steroids [12].

Finally, rituximab is known to be a very expensive drug. Rituximab may be both more effective and safer than steroids, but we must pay attention to medical costs. If the semiannual single fixed low-dose rituximab therapy can reduce the adverse effects of both rituximab and steroids as well as reduce costs and be as effective as conventional doses of rituximab treatment, it may be possible to consider starting rituximab therapy earlier. This is the first report of the usefulness of semiannual single fixed low-dose rituximab therapy in steroid-dependent MCD.

\section{Acknowledgement}

All authors are very grateful to medical staff, who understood the clinical importance of this study and provided high-quality data in Division of Nephrology, Department of Medicine, Yachiyo Medical Center, Tokyo Women's Medical University.

\section{Statement of Ethics}

Informed consent was obtained from all individual participants included in this study. This article does not contain any studies with human participants performed by any of the authors.

\section{Disclosure Statement}

The authors declare that they have no conflicts of interest to disclose.

\section{References}

1 Fujimoto S, Yamamoto Y, Hisanaga S, Morita S, Eto T, Tanaka K. Minimal change nephrotic syndrome in adults: response to corticosteroid therapy and frequency of relapse. Am J Kidney Dis. 1991 Jun;17(6):68792.

2 Takei T, Koike M, Suzuki K, Shirota S, Itabashi M, Ohtsubo S, et al. The characteristics of relapse in adultonset minimal-change nephrotic syndrome. Clin Exp Nephrol. 2007 Sep;11(3):214-7.

3 Plosker GL, Figgitt DP. Rituximab: a review of its use in non-Hodgkin's lymphoma and chronic lymphocytic leukaemia. Drugs. 2003;63(8):803-43.

4 Wong CF. Rituximab in refractory antineutrophil cytoplasmic antibody-associated vasculitis: what is the current evidence? Nephrol Dial Transplant. 2007 Jan;22(1):32-6. 
5 Godeau B. B-cell depletion in immune thrombocytopenia. Semin Hematol. 2013 Jan;50 Suppl 1:S75-82.

6 Bagga A, Sinha A, Moudgil A. Rituximab in patients with the steroid-resistant nephrotic syndrome. N Engl J Med. 2007 Jun;356(26):2751-2.

7 Guigonis V, Dallocchio A, Baudouin V, Dehennault M, Hachon-Le Camus C, Afanetti M, et al. Rituximab treatment for severe steroid- or cyclosporine-dependent nephrotic syndrome: a multicentric series of 22 cases. Pediatr Nephrol. 2008 Aug;23(8):1269-79.

8 Iijima K, Sako M, Nozu K, Mori R, Tuchida N, Kamei K, et al.; Rituximab for Childhood-onset Refractory Nephrotic Syndrome (RCRNS) Study Group. Rituximab for childhood-onset, complicated, frequently relapsing nephrotic syndrome or steroid-dependent nephrotic syndrome: a multicentre, double-blind, randomised, placebo-controlled trial. Lancet. 2014 Oct;384(9950):1273-81.

9 Kurosu N, Sugiura H, Iwasaki C, Asamiya Y, Kojima C, Moriyama T, et al. Successful use of single-dose rituximab for the maintenance of remission in a patient with steroid-resistant nephrotic syndrome. Intern Med. 2009;48(21):1901-4.

10 Sugiura H, Takei T, Itabashi M, Tsukada M, Moriyama T, Kojima C, et al. Effect of single-dose rituximab on primary glomerular diseases. Nephron Clin Pract. 2011;117(2):c98-105.

11 Takei T, Itabashi M, Moriyama T, Kojima C, Shiohira S, Shimizu A, et al. Effect of single-dose rituximab on steroid-dependent minimal-change nephrotic syndrome in adults. Nephrol Dial Transplant. 2013 May;28(5):1225-32.

12 Miyabe Y, Takei T, Iwabuchi Y, Moriyama T, Nitta K. Amelioration of the adverse effects of prednisolone by rituximab treatment in adults with steroid-dependent minimal-change nephrotic syndrome. Clin Exp Nephrol. 2016 Feb;20(1):103-10.

13 Maloney DG, Grillo-López AJ, Bodkin DJ, White CA, Liles TM, Royston I, et al. IDEC-C2B8: results of a phase I multiple-dose trial in patients with relapsed non-Hodgkin's lymphoma. J Clin Oncol. 1997 Oct;15(10):326674.

14 Chaumais MC, Garnier A, Chalard F, Peuchmaur M, Dauger S, Jacqz-Agrain E, et al. Fatal pulmonary fibrosis after rituximab administration. Pediatr Nephrol. 2009 Sep;24(9):1753-5.

15 Kamei K, Ito S, Nozu K, Fujinaga S, Nakayama M, Sako M, et al. Single dose of rituximab for refractory steroiddependent nephrotic syndrome in children. Pediatr Nephrol. 2009 Jul;24(7):1321-8. 


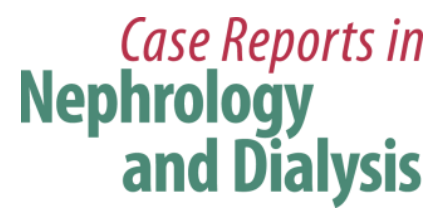

Case Rep Nephrol Dial 2018;8:230-237

DOI: $10.1159 / 000493189$

(C) 2018 The Author(s). Published by S. Karger AG, Basel www.karger.com/cnd

Usui et al.: Efficacy of Semiannual Single Fixed Low-Dose Rituximab Therapy in

Steroid-Dependent Minimal Change Nephrotic Syndrome: A Case Series
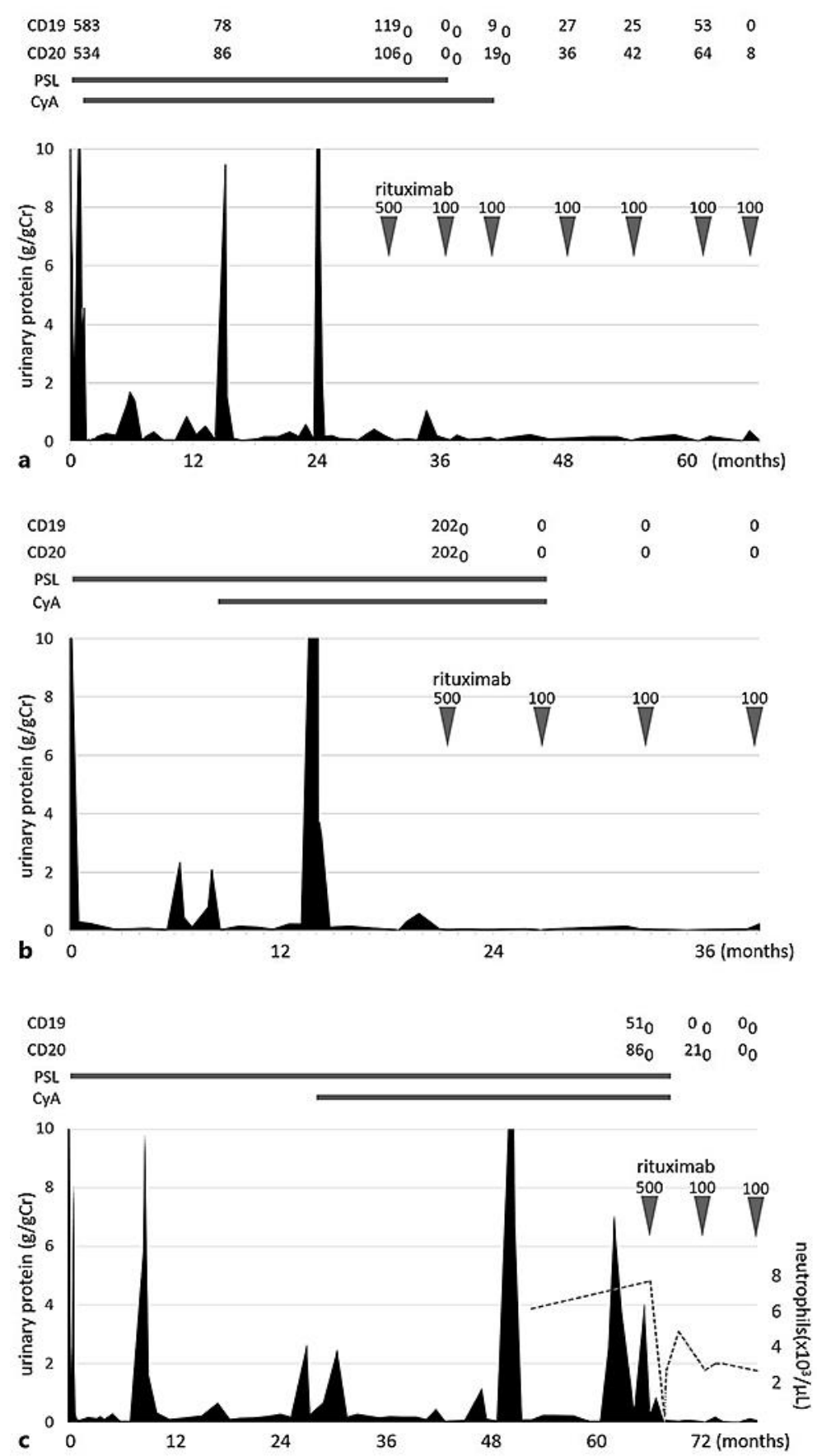

Fig. 1. The clinical course of case 1 (a), case 2 (b), and case 3 (c). CD19/CD20 rows depict CD19/CD20positive B-cell counts per microliter in peripheral blood. Hanged down figure "0" in CD19/CD20 rows means completely depleted CD19/CD20-positive B-cell counts 2 weeks after single normal-/low-dose rituximab infusion. Horizontal lines of PSL and CyA signify the duration of, respectively, prednisolone and cyclosporine A use. Dotted line in case 3 indicates neutrophil counts. 


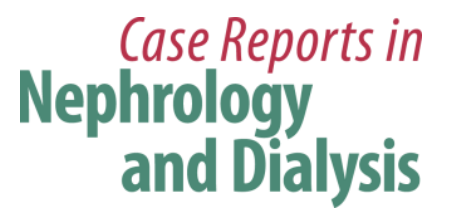

Case Rep Nephrol Dial 2018;8:230-237

DOI: $10.1159 / 000493189$

(C) 2018 The Author(s). Published by S. Karger AG, Basel www.karger.com/cnd

Usui et al.: Efficacy of Semiannual Single Fixed Low-Dose Rituximab Therapy in

Steroid-Dependent Minimal Change Nephrotic Syndrome: A Case Series

Table 1. Summarized profiles of the three cases

\begin{tabular}{lllll}
\hline Case & BW, kg & BMI & BSA, m² & $\begin{array}{l}\text { Previous treat- } \\
\text { ment }\end{array}$ \\
\hline 1 & 59.3 & 19.4 & 1.72 & CyA, LDL-A \\
2 & 59.7 & 19.3 & 1.73 & CyA \\
3 & 54.7 & 20.1 & 1.60 & CyA \\
\hline
\end{tabular}

Listed data of body weight (BW), body mass index (BMI), and body surface area (BSA) were measured at the time of first rituximab infusion. CyA, cyclosporine A; LDL-A, low-density lipoprotein absorption. 